\title{
IMPACT OF ONLINE CLASSES ON THE HEALTH AND WELLBEING OF YOUNG LEARNERS
}

\author{
Rahul Sawhney ${ }^{1}$, Pranvat Singh ${ }^{2}$, Govind Agarwal ${ }^{3}$, Shashank Sharma ${ }^{4}$, Dhanush B ${ }^{5}$, Manali Karmakar ${ }^{6 *}$ \\ ${ }_{1,2,3,4,5}$ B.Tech (Computer Science Engineering), Vellore Institute of Technology, Chennai, India; ${ }^{6 *}$ Assistant Professor, \\ Vellore Institute of Technology, Chennai, India. \\ Email: ${ }^{1}$ rahulsawhney235@gmail.com, ${ }^{2}$ rupindersinghraina@gmail.com, ${ }^{3}$ govind01pna@gmail.com, \\ ${ }^{4}$ shrmshashank209@gmail.com, ${ }^{5}$ dhanush11balaji@gmail.com, ${ }^{6 *}$ manali.karmakar@vit.ac.in
}

Article History: Received on $8^{\text {th }}$ February 2021, Revised on $10^{\text {th }}$ August 2021, Published on $16^{\text {th }}$ August 2021

\begin{abstract}
Purpose of the study: The paper discusses the impact of digital education on the health and well-being of students who have been taking online classes since the onset of COVID-19. The paper also investigates the authenticity of the media reports that have been reporting about the decline in students' health due to the extensive presence of screen time.

Methodology: The study is primarily descriptive research with a qualitative and quantitative investigation of the narratives related to health issues such as impaired cognitive functions, eye problems, orthopaedic disorders, insomnia, depression, and anxiety. Google form as an online survey tool is used to collect data later compared with the media reports to conclude.
\end{abstract}

Main Findings: The findings conclude that students' responses corroborate with the narratives of emergent pathological culture reported by news agencies like The Times of India and The Hindu.

Application of the study: The present study will help sensitise the stakeholders of the society about the detrimental impact of online classes that might create ground for adopting immediate corrective measures for protecting the future of our nation.

Novelty/ Originality of the study: The study's novelty lies in its approach to offer a comparative study of the media reports and the students' responses to cognize the severity of the evolving health issues amidst the pandemic.

Keywords: Online Classes, Media Reports, Mental Health and Physical Ailments, Young Learners.

\section{INTRODUCTION}

The world today is going through a phase of ontological insecurity and uncertainties triggered by COVID-19. Every aspect of human life has been severely affected by the ongoing pandemic. Studies conducted in the area of mental health and disability have suggested that although the "COVID-19 pandemic does not fit into prevailing Post-Traumatic Stress Disorder (PTSD) modals or diagnostic criteria, yet emerging research shows traumatic stress symptoms as a result of this ongoing global stressor. Therefore, COVID-19 could lead to PTSD symptomology" (Brigland et al., 2021, p. 1; Greenberg \& Rafferty, 2021). The pandemic has brought significant changes in the life of millions of students throughout the world. Schools and colleges have been closed to prevent the spread of the pandemic, and there is no certainty as to when the students can re-experience campus life. Needless to say, the government, in its wisdom, has continued to insist that educational institutions should remain closed; however, this strategy has far-reaching consequences on the academic and social life of students throughout the globe.

Across the world, including India, great emphasis has been laid to ensure continuity of educational instruction to prevent students from losing an academic year. As a result, education through digital means or online education has become the norm of the day. Online education may be defined as education through electronic modes where relevant educational material is made available through text files, animated or audio files, streaming videos, and images. Every student who has a computer and a broadband connection can avail the opportunity to learn through online modes (Mangis, 2016). Online platforms such as Byju's, Udemy, Tutorix, Vedantu, NPTEL, Edx, Microsoft Teams, G-meet, and Zoom Classes have emerged as the new mode to compensate for the in-person classroom instruction. Technology has made all this possible (Aduba \& Mayowa-Adebara, 2021). However, a country like India is grappling to solve the disparities triggered by the digitalization of education. A range of research articles is being published to draw the education policymakers and administrator's attention to the challenges of imparting education through digital mode.

In their study, Ivari et.al. (2020) examine the impact of digital education on the young generation. They argue that the practice of online education has led to the emergence and reinforcement of varieties of digital divides, such as polarization between students who are technologically equipped to make a quick transition to the digitalized education platform and those who are not. Children from diverse social backgrounds are not equivalently well equipped to embrace the digitalized future. (Livingstone \& Helspen, 2007; Agarwal, Animesh, \& Prasad 2009).

\section{Aims and Objectives}

This paper does not aim to add to the ongoing research narratives on the digital divide. Instead, the paper aims to draw society's attention to the impact of online classes on the health and well-being of the students. This is voluntary research conducted by a group of $1^{\text {st }}$-year B.tech students from the School of Computer Science and Engineering in collaboration 
with the School of Social Sciences and Languages to analyse the pros and cons of the online classes on the student community. The paper primarily aims to gauge the relevance of the new paper reports and blogs discussing the devolution of the health and mental well beings of young minds due to the sudden shift from in-person to online classes. In addition, this article intends to focus on health issues such as impaired cognitive functions, medical issues relating to eyes, orthopaedic disorders, Insomnia, isolation leading to depression and anxiety.

\section{LITERATURE REVIEW}

Jessica Mangis (2016), in her thesis, states that online education has further led to the emergence of a sedentary lifestyle resulting in "later bedtimes, longer sleep onset latency and later walking time" (p. 2-3). Mangis further argues that even though online courses have offered students the autonomy to work at their space and pace, the sedentary nature of online classes has triggered health issues such as cardiovascular diseases, type 2 diabetes, and depression. Similarly, an empirical study was conducted at the Netaji Subhas University of Technology, New Delhi, to analyze issues related to online classes, such as content delivery, interaction, assessment, and health issues (Chakraborty et al., 2021). A comparative analysis was made to understand the impact of online classes on the youth of the institute. The study has concluded that students could not cope with the sudden transition in their lifestyle and academia. Many students reported suffering from mental ailments of varying severity. Depression, anxiety, and suicidal thoughts are the prime mental health issues encountered by the students. Below a detailed review is provided on the existing research narratives on the correlation between ample screen time and health deterioration of the young learners.

\section{Impaired Cognitive Function}

Cognition is essentially defined as "the mental processes involved in acquiring and processing information necessary for everyday life" (Magni and Bilotta, 2016, p. 411). The word cognition is derived from the Latin word Cognoscere which denotes getting to know or recognising. Cognitive development can thus be briefly construed as the development in the thought processes, problem-solving skills, reasoning, and decision making from childhood to adolescence and adulthood. (Bayne et al., 2019). People with cognitive deficits experience loss of memory, feeble attentiveness, trouble in cognizing information, difficulty in recognizing people, places, or things, and experience sudden and severe mood swings. Such conditions may be referred to as cognitive impairment, a neurological disability that hinders the processing and retrieving of information effectively (Shree \& Shukla, 2016)

Alice G. Walton (2018), in her blog piece "Less Screen Time Linked to Better Cognition in Kids: Study", states:

When they spend more than two hours on screens every day, they tend to perform more poorly on tests of cognition. They may not come as a total shock, given the research in recent years - and much anecdotal evidence - but it is nice to have more confirmation in the form of research findings.

"The study, by researchers at Children's Hospital of Eastern Ontario Research Institute, looked at data from 4,500 children aged 8-11 from 20 locations across the U.S. Their parents answered questions about their usual screen use, their sleep, and time spent in physical activity. The children also completed a cognitive test, which measured executive function, attention, working memory, episodic memory, language, and processing speed. (para 1-2)

The average amount of screen time recommended per day is 3.6 hours. Unfortunately, not many of the students have the privilege to comply with the recommended screen time (two hours or less per day), sleep (9-11 hours/night), and physical activity (60 minutes/day). Walton's explanation corroborates research findings on the detrimental effects of the longer screen time published in the prestigious journal The Lancet Child and Adolescent Health (Walsh et al., 2018). In their study, Amrit Kumar Jha and Alisha Arora (2021) argue that online education has wreak havoc on the growing brain of children. They state that e-learning poses an adaptability risk for young learners. Multi-method screen exposure leads to:

Structural changes such as reduced volume of the cortex with loss of integrity pertaining to the white matter region and decreased grey matter in prefrontal regions viz. the right frontal pole and anterior cingulate cortex. Such alternations consequently impede attention competence, processing speed, verbal intelligence, and sustained attention respectively (pg 1).

Online learning produces cognitive overload that reduces the "quality of comprehension, prioritization, and deep-level processing of incoming information", thus leading to insufficient processing and internalization of content disseminated by the course instructor. Mylene Mendoza (2020) has introduced the concept of "Zoom fatigue" to discuss the mental fatigue experienced by learners during online classes (para 2). Similar to Jha and Arora, Mendoza states that our brain has to put extra effort to stay attentive in online classes, which leads to mental fatigue resulting in students' failure to stay focused. Mendoza further argues that the transition of the traditional classes into a virtual space has made the student more conscious of their facial expressions and postures. "Online classes through video conferencing put all your faces side by side on one screen, even when you are not speaking" (para 6). This order of extensive exposure to peers and course-instructors adds to the cognitive overload that blocks the unimpeded information processing. 


\section{Computer Vision Syndrome}

American Optometric Association defines computer vision syndrome as a group of eye-and-vison-related problems triggered by prolonged digital device usage. The association argues that the unique characteristics and the high visual demands of the computer, and the unregulated screen time make individuals susceptible to vision-related syndrome. Studies of scholars like Swati Agarwal et al. (2021) and Chee Wai Wong et al. (2021) discuss a range of ocular problems like discomfort leading to tearing, tired eye, burning sensation, headache, blurring vision, redness, and double vision that has augmented during the COVID-19 pandemic.

\section{Insomnia}

Medically, Insomnia may be defined "by the presence of an individual's report of difficulty with sleep" (Ruth, 2007). Sleep is a state in which the body rests by reducing its interaction with its surroundings, which helps the body recover from daily fatigue. Sleep deprivation and irregular sleep cycle can have a negative impact on memory, concentration, and performance. Rosenberg et al. (2019) stated that spending a lot of time in front of digital screens has severely affected sleep quality, and they find it difficult to fall asleep. Morin (2021) argues that online work culture has generated for many people "significant stress, anxiety, and worries about health, social isolation, employment, finances as well as the challenge of combining work and family obligations. Such a major stressful life event is also likely to have impaired sleep and circadian rhythms, at a time when healthy sleep is particularly important to cope adaptively with this crisis and uncertainty about the future" (p. 346). In a similar vein, Ruchir Khare et al. (2020) state that during COVID-19, the extension of the screen time has an adverse effect on the sleep health of the students. The blue light emitted from digital devices is known to problematize the normative functioning of the endogenous circadian melatonin release. The disturbance in hormonal functioning leads to an increase in evening alertness, sleep latency, and the timing of rapid eye movement sleep.

\section{Orthopaedic Pains}

Although a few blog pieces are written on the interconnectivity between orthopaedic pains and online classes, we cannot retrieve scientific research articles on this issue. Therefore, the following section on the findings might be a humble attempt from our end to fill in the research gap.

\section{Depression and Anxiety}

Depression is an affective phenomenon. It may be defined as the state of stativeness that ruptures the patient's understanding of selfhood. People suffering from depression experience sadness and loneliness for no known reason. Nadar Salari et al. (2020) argue that the COVID-19 pandemic has a severe impact on the mental health and well-being of the population. Social isolation due to online classes contributed to the risk of clinical depression as one cannot interact with teachers and academic peers (Notivol et al., 2021; Rajkumar 2020). The Head of the Department of Andhra Medical College, P Venugopal states that in schools and colleges, students have free slots which they can use for socializing. Unfortunately, online classes offer little scope for this, thus causing strain in the growing minds. Internet addiction can cause social isolation, which ultimately leads to depression. Jha and Arora (2020) add to the ongoing mental health concern by stating that online classes impair the social cognitive abilities of learners. Online classes hinder the normative development of affective factors such as empathy, teaming, and peer relationships, thus contributing to isolation and alienation that are medically conceived to be the etiology of depression and anxiety.

From the above review of the existing research, it may be concluded that although health issues in the current era of the global pandemic have received satisfactory attention, limited research has been produced to understand the correlations between the students' responses to the health issues triggered by online classes and media narratives. Thus, this research paper attempts to contribute to the comparative study of subjective responses and media discourse.

\section{METHODOLOGY}

The study is a descriptive research with quantitative and qualitative investigation of the students' response and media narratives on the emerging mental health and physical health issues. To gain insight into the health problems being faced by students, we have specifically tried to elicit responses from students in the age group ranging from 17 to 20 years pursuing engineering degrees at our university who are supposed to sit in front of the computer for more than 8 hours a day. Google form as an online survey tool is used to collect data that is later compared with the media reports to arrive at a conclusion. A detailed questionnaire was circulated. The initial aim of the questionnaire was to collect data related to the health issues frequently reported by news agencies such as Times and The Hindu. Later, we planned to make provision for the students to state about the health issues in addition to what is already known. 184 students from our university have participated in our survey.

\section{FINDINGS AND DISCUSSIONS}

The hauntological presence of insecurity and uncertainties has proved to be detrimental to the learners' mental health. The data analysis has shown that $81 \%$ of the students have stated that online classes can act as an add-on to education, but it cannot be a complete substitution of the real-life classroom. The respondents state that online classes are held 
throughout the day, leaving little room for extracurricular activities. Furthermore, $65.2 \%$ of the students have agreed that online classes have negatively impacted cognitive processing, thus leading to poor academic performance. The students reported that the computer screen contains a lot of information, which is difficult to fathom and extremely difficult to comprehend. It creates chaos in their minds, thus leading to stress and exhaustion. The students find it extremely difficult to understand which information must be assimilated and what they can safely ignore. Hence, we can conclude from the data that students' cognitive filtration of the information is hindered in the online classes (Grabinger et al., 2008).

Online classes are negatively affecting academic performance 184 responses
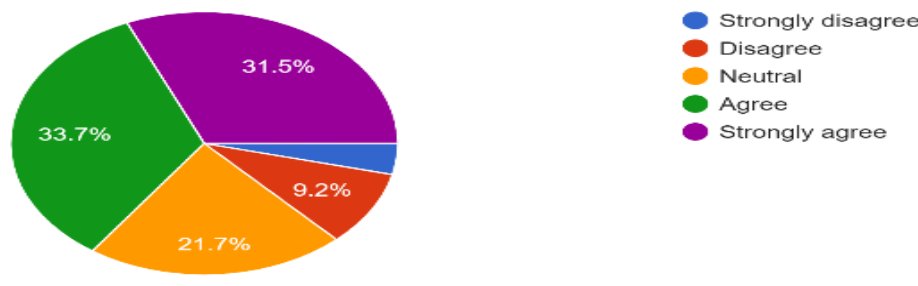

Figure 1: Graphical Representation of Impaired Cognitive Functioning

Source : Author[s]: Rahul Sawhney

The present data corroborates with the reports published on the website of reputed news agencies like The Times of India and India Today. In a blog piece titled, "Online Classes Causing Stress, impacting the health of the students", Kritika Sharma (2020) confirms that in a survey, it is identified that $55 \%$ of students are suffering from issues such as fatigues, irritability, loss of confidence, and lack of motivation due to prolong online classes during the pandemic. A similar argument is presented by Shelly Anand (2020) on the webpage of India Today.

\section{Computer Vision Syndrome}

Online classes undoubtedly allow students to catch up on the classes they have missed. Still, prolonged exposure to screens without a break is causing severe health issues like dry eye syndrome, burning sensation of eyes, loss of focus flexibility, nearsightedness, retinal damage, etc. Nowadays, eye problems are becoming more and more common. 6 out of 10 people wear spectacles. Such a statistic sends a frisson down the spine of most parents concerned about their children's health and well-being. We conducted a survey that aims to determine the number of people who feel strain in their eyes while attending online classes. Below are our findings.

$86.5 \%$ of the students feel strain in their eyes and feel the requirement for eye lubricant or glasses.

Do you feel strain in your eyes due to online classes?

184 responses

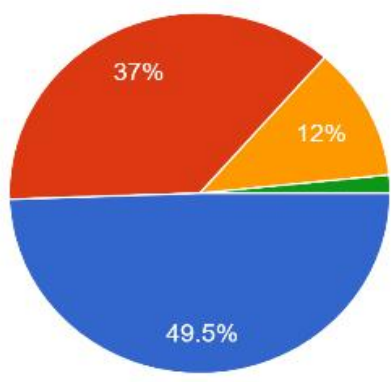

Figure 2: Pictorial Representation of the Data

Source: Author[s]: Pranvat Singh

Computer screens and digital devices lead to clinical issues such as eye strain, eye fatigue, and Insomnia. One of the main reasons for these conditions is the excessive exposure to blue light which is emitted by the screens of digital devices. It is interesting to note that both the sun and indoor lights emit some level of blue light, but our eyes have inbuilt mechanisms to reduce the exposure to blue light occurring naturally. Staring at the screen for a long time can cause 
irritation and dryness in the eyes. According to various studies, people blink far less often while concentrating on screens, which leads to dryness in the eyes. For a clear vision, a clear and stable tear film on the eye must be maintained. The study that we conducted also agrees with the above statement since $60 \%$ of the respondents stated that they experience eye dryness and irritation in their eyes (Iwasinski, 2019). According to our case study, 50.5\% of students do not use blue lenses, and $16.8 \%$ of the respondents have never heard of it. The facts are alarming.

Do you own a pair of blue lens glasses?

184 responses

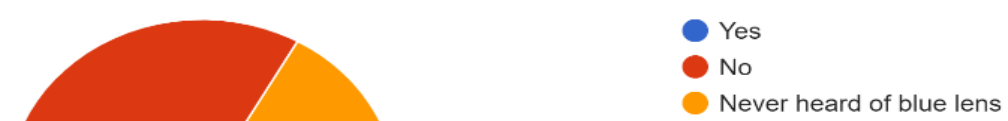

Figure 3: Pictorial Representation of the Data

\section{Source: Author[s]: Pranvat Singh}

The detrimental effects of blue light are also discussed by an ophthalmologist whose interview is published in The Hindu. The medical expert states that during COVID-19, students have frequently visited his clinic with complaints of dryness in their eyes and frequent blinking of eyes. These problems have arisen due to excessive screen time. He suggests that a proper viewing distance has to be maintained to avoid clinical issues. One more concerning factor linked to online classes is the blurring of vision, dry eyes, and headaches. The students, without realizing, keep the gadgets close to their eyes which puts excessive strain on the muscles of the eyes and ultimately leads to computer vision syndrome. Our study corroborates with Saleem et. al. (2021) study of the digital eye strain in the era of the COVID-19 pandemic. Bhattacharya et al. argue that due to the lockdown, the online classes have started without specific guidelines.

Students have to stay online facing the screen for eight to twelve hours to cope with the institution's demand. "These devices cause harm by emitting short high energy waves that can penetrate eyes and can eventually contribute to photochemical damage to the retina cells, a making an individual vulnerable to a variety of eye problems" (p. 1709). The range of eye problems that emerge from extensive online interaction is clinically termed Digital Eye Strain (DES) or computer vision syndrome. Renowned newspaper The New Indian Express (2020) published a blog titled "Eyestrain from Digital Classes: A Major Health for Students" that discusses the ophthalmological problems encountered by students during the pandemic. The bog piece captured the concerns of pediatric ophthalmologist Doctor Sanitha Sathyan. Dr Sathyan confirms the above-stated facts and sheds light on the dire situation. The expert medical states:

Cases are rising, and some are even detected with computer vision syndrome. Last week alone, I have seen around 5-10 cases of children with issues of blurring of vision, dry eyes, and headache. Most of the time, we find kids keeping the gadgets close to their eyes. This is bad for their eye muscles and when they put excessive effort, it causes blurring of vision. (para 4)

\section{Insomnia}

According to our survey, $62 \%$ of the students feel drowsy and struggle to concentrate during online classes. This was caused mainly due to changes in the sleep pattern and sleep deprivation. 54.9\% of the students said that they are going through various stages of Insomnia. As there are no fixed hours for the classes, the easy availability of recorded lectures gives ample scope to the students to use the digital devices at any time of the day. An unintended consequence of this facility is that the students use time, otherwise available to them for relaxation, self-care, and socializing, to revise their lectures, thus spending substantial time before their screens. This leads to a reduction in the number of hours available for sleep, thereby affecting the students' performance the following day.

Most of the respondents state that their quality of sleep is affected due to their bedrooms being converted into a stressful place of work. The respondents stated that their minds are mentally conditioned to consider the bedroom as a place for relaxation. However, online classes have changed this perception, and after a day full of stressful online classes, they find it very difficult to sleep in the same place. Most of the respondents stated that this change has severely affected the quality of sleep. According to our survey, approximately $60.9 \%$ of the students state that online classes have severely affected sleep quality. 
Do you feel sleepy during online classes?

184 responses

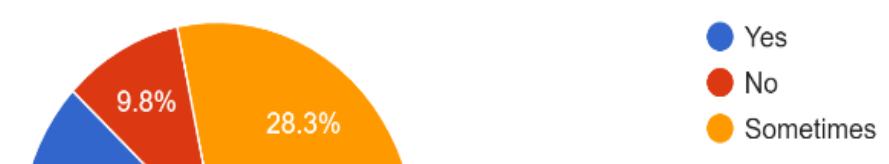

Figure 4: Pictorial Representation of the Data

Source: Author[s]: Govind Agarwal

Have your sleeping hours changed after attending online classes?

184 responses

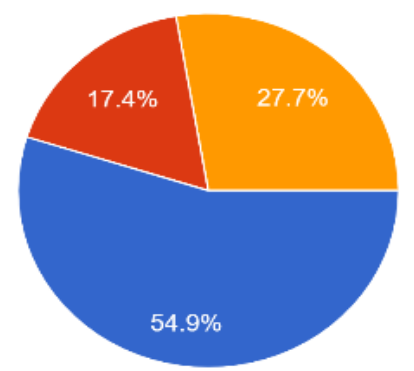

Reduced

Increased

Remained the same

Figure 5: Pictorial Representation of the Data

Source: Author[s]: Govind Agarwal

Online classes have severely affected the quality of sleep

184 responses

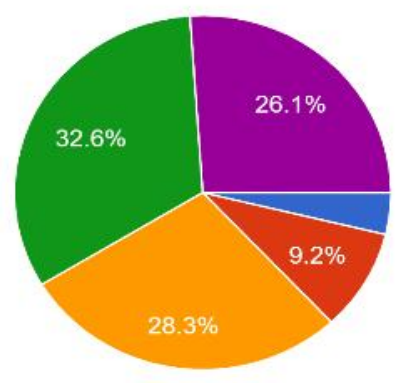

Strongly Disagree

Disagree

Neutral

- Agree

Strongly Agree

Figure 6: Pictorial Representation of the Data

Source: Author[s]: Govind Agarwal 
We all know that using digital formats and the various application in the online resources require time and understanding of the technology. Most of the respondents state that using these platforms and communicating with the teachers and peers create anxiety in their minds, which ultimately disrupts their sleep patterns and sleep quality. In addition to this, simple tasks like communicating with the teachers and peers take a lot of time compared to physical interaction. These two circumstances have contributed to sleep deprivation, which directly affected the students' attention span. Our survey showed that 5 out of 10 people lose sleep because of these reasons and thus have a reduced attention span.

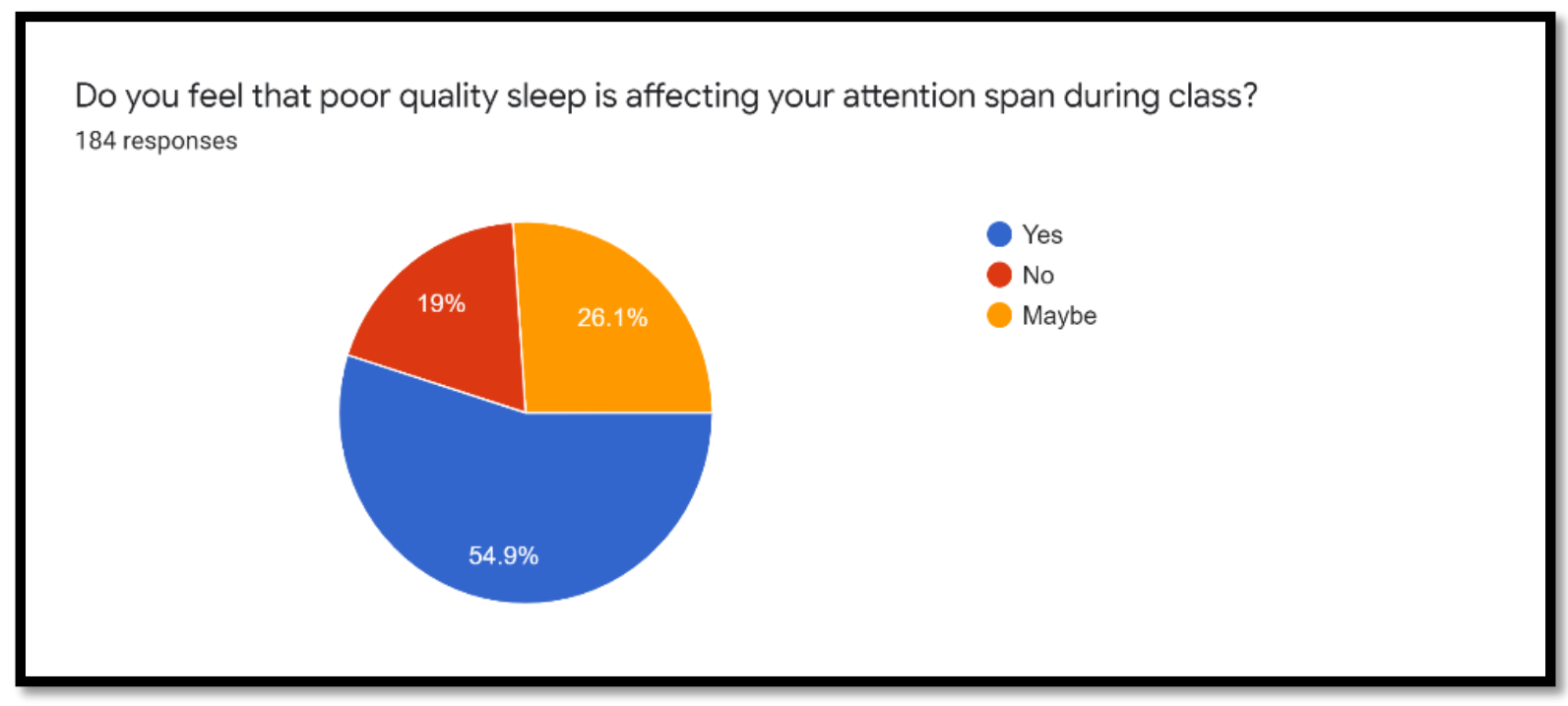

Figure 7: Pictorial Representation of the Data.

\section{Source: Author[s]: Govind Agarwal}

Through our survey, we can discover a unique problem relating to students based out of India and are presently pursuing courses online in their respective countries. Due to time zone differences, students had to change their sleeping patterns and study or attend classes at odd hours (Amarjot, 2020). This has problematized their sleep pattern and has disrupted their quality of sleep. We found various articles written on the subject where the students have highlighted these problems and their effects on their physical and mental health during our research. For example, a local newspaper circulated in Punjab recently reported the following situation:

The pandemic has been nothing short of a nightmare for most students who came back to Chandigarh in March and are studying online at their universities abroad. While erratic timings, courtesy time-zone difference, have sent their biological clocks in a tizzy, most students are losing sleep over picking between pre-recorded lectures and live lectures. A second-year student from a university in Canada, who has been here since the lockdown, said, "We are expected to be up all night and sleep during the day. It is taking a toll on our health. I feel like I am isolated from family and friends. Our university gives asynchronous lectures. The pre-recorded ones lack interaction, and if you want to be involved with the class, you need to attend live lectures.

A third-year student studying in a university in Seattle, US, is facing a similar situation. "My classes start at 9 pm. The hardest are the lectures that start at $3 \mathrm{am}$," he rues. The student added, "It's easily five hours of classes and then we have assignments and mid-terms too. The hardest thing is to sit up at wee hours to give a mid-term (exam). While some professors are benevolent to give us a 24-hour bracket to choose from, others want us to appear for exams at the designated time." (para 1-3)

\section{Orthopaedic Problems}

Our survey showed that the continuous use of digital devices for online classes has led to several orthopaedic problems in a substantially large proportion of students. The main reason for this issue is the "bad posture" characterized by an overly bent spine, slouched or slumped back, lurched shoulders, and an awkwardly bent arm or wrist (Dhar, 2020). Pains and aches are also related to the design of the laptops and the amount of time spent on the bed or poorly designed chairs at home. Our survey showed that 5 out of 10 people were suffering from neck or back pain due to the students spending long hours in an awkward position before their laptops. The problem is significantly compounded for those students whose laptop screen has inbuilt keyboards. Such devices cannot be separately arranged for efficient viewing and typing. Without the proper posture and the right kind of study desk, students complain about extreme pain in their backs, shoulders, and neck muscles because of slouching or straining for long periods. Some even experience stress, tingling sensations, headaches, muscle fatigue, and decreased performance because of bad posture. 
According to our survey, $63 \%$ of students have complained about body pain. The survey also aimed to find whether people maintain or make an effort to maintain the proper posture while attending online classes. The results were astounding. $90 \%$ of students reported not maintaining the correct posture.

Are you plagued by body pain?

184 responses

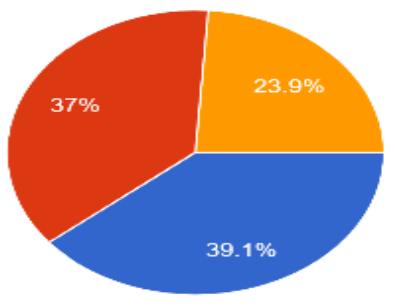

Figure 8: Pictorial Representation of the Data

Source: Author[s]: Shashank Sharma

Do you maintain the right posture during online classes?

184 responses

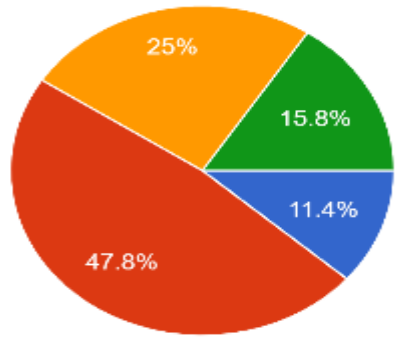

Figure 9: Pictorial Representation of the Data

Source: Author[s]: Shashank Sharma

Shobita Dhar (2020) from Times of India reports that the online health portal, Practo, records a $680 \%$ increase in orthopaedic teleconsultations from March 1 to August 31. In this context, we would like to discuss the Times of India blog piece titled "Why Students are Complaining of Aches and Pain," which attempts to bring the public's attention to the orthopaedic problems of 17 years old students Mihika Verma and Krishna Mathur.

Mihika Verma, 17, a student of Bal Bhavan in Delhi’s Mayur Vihar, said she's on painkillers to manage the pain in her neck and frequent headaches from staring at the screen. She sits for 8 hours every day in front of the monitor to attend school classes, tuition, and home assignments. "For two months, July and August, I had a headache every day. Because of Covid, I couldn't go out to get my eyes tested, but when I finally did, my number had increased, which was causing the headaches," said Verma, now diagnosed with a neck spasm.

Krishna Mathur, 17, a student at a well-known school in Noida, admitted he spends 18-20 hours a day sprawled in front of a screen. "I frequently get shoulder pain, and my eyes burn. At times, I feel feverish and take a Crocin or paracetamol," said Mathur, who is preparing for SATs. ((para 3-4)

\section{Depression and Anxiety}

The study shows that approximately $15.8 \%$ of the respondent agree that online classes may be one of the leading causes for triggering depression. In addition, the data reveals that $82.1 \%$ of the students firmly believe that academic productivity has significantly declined due to the forced confinement and online classes. Nearly $65.2 \%$ of students believe that online classes are causing a negative impact on academic life. 
Online classes are leading to some form of depression

184 responses

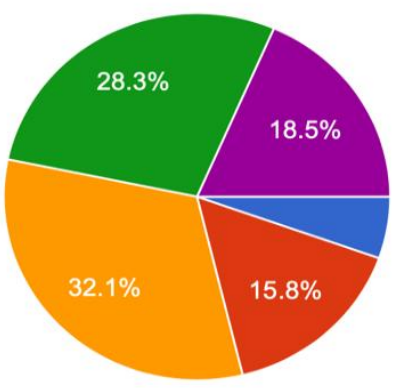

Strongly disagree

Disagree

Neutral

Agree

Strongly Agree

Figure 10: Pictorial Representation of the Data

Source: Author[s]: Dhanush B

Do you feel less productive without interacting with academic peers?

184 responses

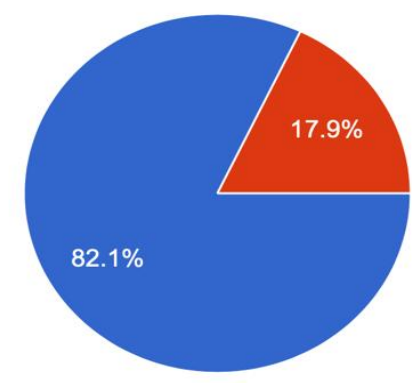

$$
\begin{aligned}
& \text { Yes } \\
& \text { No }
\end{aligned}
$$

Figure 11: Pictorial Representation of the Data

Source: author[s]: Dhanush B

Online classes are spread throughout the day leaving us with little time to focus on extracurricular activities

184 responses
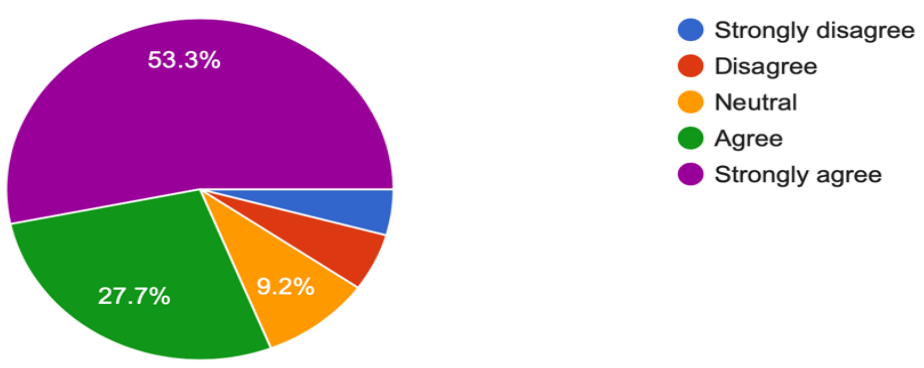

Figure 12: Pictorial Representation of the Data

Source: Author[s]: Dhanush B 
Online classes are negatively affecting academic performance

184 responses

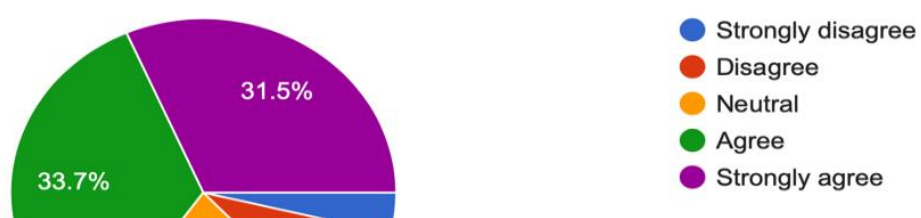

Figure 13: Pictorial Representation of the Data

Source: Author[s]: Dhanush B

Online classes have forced children and their parents to change daily routines. Video calls may potentially replace inperson classes, but it affects an individual's mental and physical well-being. A similar narrative is captured in the student's news sites named "The Northern Light", operated by Portage Northern High School:

Nationwide, $29 \%$ of parents studied in a Gallup poll said their child is "already experiencing harm" to their emotional or mental health because of social distancing and closures. However, $14 \%$ said their child could continue online school for a few more weeks until their mental health suffers. The online school doesn't have the social element of the in-person school, which is crucial to students' social and emotional learning.

In that same Gallup poll, $45 \%$ of parents said that separating their child from classmates and teachers is a "major challenge." Junior Maggie Gross agrees. "Lack of physical interaction has killed my mental stability," she says.

Online video calls are socially draining as it takes more work to pick up social cues and not see people's faces and bodies in real-time. A National Geographic article explains that "a typical video call impairs these ingrained abilities, and requires sustained and intense attention to words instead." This is referred to as Zoom fatigue."

School routines are essential coping mechanisms for children having psychological issues. However, when schools are closed, they lose an anchor in life, and their symptoms could relapse. "Going to school had been a struggle for [some children with depression] before the pandemic, but at least they had school routines to stick with, "Now that schools are closed, some of them refused to take showers or eat food some have difficulties in sleeping. When the school reopens, children suffering from depression might have a problem adjusting to everyday life (para 2-5).

\section{CONCLUSION}

This study stands as a reference for considering the health issues while designing online courses and classes in the near future. The study conclusively proves that it is imperative for educational administrators, institutes, and government to earnestly consider the social and medical impact online education has on students' physical and mental health and recommend suitable strategies to lessen the impact of these issues. Our research shows that the majority of people prefer in-person classes over online classes. However, considering the impact of the pandemic, a collaborative approach involving teachers, students, and parents can be initiated to make online teaching more meaningful. In addition, specific strategies need to be designed to cater to students with cognitive impairment and other disabilities.

Course design, online presentation, and the quantity and quality of the information provided have to be restructured to ensure that the students don't spend most of their quality time in front of their screens. A conscious effort should be made to encourage students to take up extracurricular activities, and excessive overload of the academic curriculum should be avoided. More emphasis should be laid on group activities and group learning to ensure that students don't feel isolated to the extent possible. In addition, parents should be sensitized about the infrastructures and study postures that need to be maintained while doing classes.

Online classes have affected the students' health in different ways, as mentioned in the research article. Students face many vision issues like dry eye syndrome, burning sensation of eyes, loss of focus flexibility, nearsightedness, and retinal damage due to the prolonged exposure to screen. In addition, spending a lot of time in front of digital screens has severely impacted the quantity of sleep, and in some cases, it also leads to 
difficulty in falling asleep. Due to this sleep deprivation, many teenagers felt symptoms of Insomnia and depression. But depression has not come into play just because of sleep deprivation but also because of the isolation faced by students mentally due to online classes. The issues need to be addressed explicitly if online education has to become a viable option for imparting education to every nook and corner of our vast country.

\section{LIMITATIONS AND SCOPE FOR FURTHER STUDY}

This study focused on understanding the range of mental health and physical health issues of students of one institute in an urban setting. The survey is not extended to the other rural and semi-urban settings to understand how the associated variables like the socio-cultural, demographic location and the students' family environment might influence the students' responses and their correlation to the evolving media narratives. Further study may be conducted to understand how the variables mentioned above might influence the students' responses from diverse institutions and geographical locations. In fact, the study has not gone for a detailed investigation of the sub-issues related to the above-stated health issues. The present study offers a broad overview of the health issues. Hence, further study may be conducted to understand the associated health issues related to cognitive impairment, ocular problems, depression, insomnia, and orthopaedic pain

\section{THE CONTRIBUTION MADE BY EACH AUTHOR}

Rahul Sawhney ${ }^{1}$-Collected and interpreted the data on cognitive impairment.

Pranvat Singh ${ }^{2}$ - Collected and interpreted the data on the computer-vision problem.

Govind Agarwal ${ }^{3}$ - Collected and interpreted the data on Insomnia.

Shashank Sharma ${ }^{4}$ - Collected and interpreted the data on orthopaedic issues.

Dhanush $\mathrm{B}^{5}$ - Collected and interpreted the data on depression and anxiety.

Manali Karmakar ${ }^{6}$ - Collated the data of the entire survey and have given the writing the shape of a scientific research paper. The data was collected under her supervision.

\section{REFERENCES}

1. Agarwal, S., Bhartiya, S., Mithal, K., Shukla, P., \& Dabas, G. (2021). Increase in ocular problems during COVID-19 pandemic in school going children- a survey based study. Indian journal of ophthalmology, 69(3), 777-778. https://doi.org/10.4103/ijo.IJO_2981_20

2. Aduba, D. E., \& Mayowa-Adebara, O. (2021). Online Platforms Used for Teaching and Learning during the COVID-19 Era: The Case of LIS Students in Delta State University, Abraka. International Information \& Library Review, 1-36. https://doi.org/10.1080/10572317.2020.1869903

3. Agarwal, R., Animesh, A., \& Prasad, K. (2009). Research Note-Social Interactions and the "Digital Divide": Explaining Variations in Internet Use. Information Systems Research, 20(2), 277-294. https://doi.org/10 $.1287 /$ isre. 1080.0194

4. Anand, S. (2020). Are online classes wearing children out? India Today. https://www.indiatoday.in/india-todayinsight/story/are-online-classes-wearing-children-out-1743399-2020-11-23

5. Bridgland, V. M. E., Moeck, E. K., Green, D. M., Swain, T. L., Nayda, D. M., Matson, L. A., Hutchison, N. P., \& Takarangi, M. K. T. (2021). Why the COVID-19 pandemic is a traumatic stressor. PLOS ONE, 16(1), e0240146. https://doi.org/10.1371/journal.pone.0240146

6. Bhattacharya, S., Saleem, S., \& Singh, A. (2020). Digital eye strain in the era of COVID-19 pandemic: An emerging public health threat. Indian Journal of Ophthalmology, 68(8), 1709. https://doi.org/10.41 03/ijo.ijo 1782_20

7. Bueno-Notivol, J., Gracia-García, P., Olaya, B., Lasheras, I., López-Antón, R., \& Santabárbara, J. (2021). Prevalence of depression during the COVID-19 outbreak: A meta-analysis of community-based studies. International Journal of Clinical and Health Psychology, 21(1), 100196. https://doi.org/1 $\underline{0.1016 / j . i j c h p .2020 .07 .007}$

8. Bayne, T., Brainard, D., Byrne, R. W., Chittka, L., Clayton, N., Heyes, C., Mather, J., Ölveczky, B., Shadlen, M., Suddendorf, T., \& Webb, B. (2019). What is cognition?. Current biology : CB, 29(13), R608-R615. https://doi.org/10.1016/j.cub.2019.05.044

9. Chakraborty, P., Mittal, P., Gupta, M. S., Yadav, S., \& Arora, A. (2020). Opinion of students on online education during the COVID -19 pandemic. Human Behavior and Emerging Technologies, O(0), 1-9. https://doi.org/10.1002/hbe2.240

10. Cherry, Kendra. (2019). "Cognitive Psychology: The Science of How We Think." Very Well Mind. https://www.verywellmind.com

11. Dhar, S. (2020). A 500\% spike in online medical consults since March, finds a survey. The Times of India. https://timesofindia.indiatimes.com/home/sunday-times/a-500-spike-in-online-medical-consults-since-marchfinds-a-survey/articleshow/76548008.cms 
12. Greenberg, N., \& Rafferty, L. (2021). Post-traumatic stress disorder in the aftermath of COVID -19 pandemic. World Psychiatry, 20(1), 53-54. https://doi.org/10.1002/wps.20838

13. Grabinger, R.S., Aplin C., \& Brenner-Ponnappa, G. (2008).Supporting Learners with Cognitive Impairments in Online Environments. TechTrends, 52(1), 63-69. https://doi.org/10.1007/s11528-008-0114-4

14. Iwasinski, A. (2019). Do blue light glasses really work? Eye experts weigh in. WKMG. https://www.clickorlando.com/health/2019/11/18/do-blue-light-glasses-really

15. Jha, A. K., \& Arora, A. (2020). The neuropsychological impact of E-learning on children. Asian journal of psychiatry, 54, 102306. https://doi.org/10.1016/j.ajp.2020.102306

16. Livingstone, S., \& Helsper, E. (2007). Gradations in digital inclusion: children, young people and the digital divide. New Media \& Society, 9(4), 671-696. https://doi.org/10.1177/1461444807080335

17. Iivari, N., Sharma, S., \& Ventä-Olkkonen, L. (2020). Digital transformation of everyday life - How COVID-19 pandemic transformed the basic education of the young generation and why information management research should care?. International journal of information management, 55, 102183. https://doi.org/10.1016 j.ijinfomgt.2020.102183

18. Khare, R., Mahour, J., Ohary, R., \& Kumar, S. (2021). Impact of online classes, screen time, naps on sleep, and assessment of sleep-related problems in medical college students during lockdown due to coronavirus disease19 pandemic. National Journal of Physiology, Pharmacy and Pharmacology, 11(1), 1. https://doi.org/10.54 55/njppp.2021.10.09235202006092020

19. Kaur, Amarjot. (2020). Students lose sleep for overseas online classes. The Tribune. https://www.tribuneindia.com/news/coronavirus/students-lose-sleep-for-overseas-online-classes-145272

20. Morin, C. M., \& Carrier, J. (2021). The acute effects of the COVID-19 pandemic on insomnia and psychological symptoms. Sleep Medicine, 77, 346-347. https://doi.org/10.1016/j.sleep.2020.06.005

21. Mangis, Jessica. (2016) "Online learning and the effects on functional health: a pilot study" (2016). EWU Masters Thesis Collection. https://dc.ewu.edu/theses/386

22. Magni, G., \& Bilotta, F. (2016). Postoperative Cognitive Dysfunction. In H. Prabhakar (Ed.), Complications in Neoroanesthesia (pp. 411-422). Academic Press. https://10.1016/B978-0-12-804075-1.00041-9

23. Mendoza, Mylene. (2020). This is what happens to your brain during online classes. Lifestyle. https://www.candymag.com/lifestyle/what-happens-brain-online-classes-a00306-20200813

24. Newfield, P. (2009). Postoperative cognitive dysfunction. F1000 Medicine Reports, 1, 0. https://doi.org/1 $0.3410 / \mathrm{m} 1-14$

25. Bueno-Notivol, J., Gracia-García, P., Olaya, B., Lasheras, I., López-Antón, R., \& Santabárbara, J. (2021). Prevalence of depression during the COVID-19 outbreak: A meta-analysis of community-based studies. International journal of clinical and health psychology : IJCHP, 21(1), 100196. https://doi.org/10.10 16/j.ijchp.2020.07.007

26. Rajkumar, R. P. (2020). COVID-19 and mental health: A review of the existing literature. Asian Journal of Psychiatry, 52, 102066. https://doi.org/10.1016/j.ajp.2020.102066

27. Rosenberg, R., Murphy, P., Zammit, G., Mayleben, D., Kumar, D., Dhadda, S., Filippov, G., LoPresti, A., \& Moline, M. (2019). Comparison of Lemborexant With Placebo and Zolpidem Tartrate Extended Release for the Treatment of Older Adults With Insomnia Disorder. JAMA Network Open, 2(12), e1918254. https://doi.org/10.1001/jamanetworkopen.2019.18254

28. Roth, T. (2007). Insomnia: Definition, Prevalence, Etiology, and Consequences. Journal of Clinical Sleep Medicine, 3(5 suppl), 7-10. https://doi.org/10.5664/jcsm.26929

29. Salari, N., Hosseinian-Far, A., Jalali, R., Vaisi-Raygani, A., Rasoulpoor, S., Mohammadi, M., Rasoulpoor, S., $\&$ Khaledi-Paveh, B. (2020). Prevalence of stress, anxiety, depression among the general population during the COVID-19 pandemic: a systematic review and meta-analysis. Globalization and Health, 16(1), 2-11. https://doi.org/10.1186/s12992-020-00589-w

30. Shree, A., \& Shukla, P. C. (2016). Intellectual Disability: Definition, classification, causes and characteristics. Learning Community-An International Journal of Educational and Social Development, 7(1), 9. https://doi.org/10.5958/2231-458x.2016.00002.6

31. Saleem, S., Bhattacharya, S., \& Singh, A. (2021). "Importance of effective communication during COVID-19 Infodemic"Are we prepared enough? A reality check! Journal of Family Medicine and Primary Care, 10(2), 1068. https://doi.org/10.4103/jfmpc.jfmpc_2072_20

32. Sharma, Kritika (2020). As online classes drag on, fatigued students losing interest, becoming asocial. The Print. https://theprint.in/india/education/as-online-classes-drag-on-fatigued-students-losing-interest-becomingasocial-say-parents/542253/

33. Tribune News Service. (2020). Students lose sleep for overseas online classes. Tribuneindia News Service. https://www.tribuneindia.com/news/coronavirus/students-lose-sleep-for-overseas-online-classes-145272

34. The New Indian Express. (2020). Eyestrain from digital classes a major health concern for students. https://www.newindianexpress.com/cities/kochi/2020/jun/13/eyestrain-from-digital-classes-a-major-healthconcern-for-students-2155908.html 
35. Walton, A. G. (2018). How Too Much Screen Time Affects Kids' Bodies And Brains. Forbes. https://www.forbes.com/sites/alicegwalton/2018/04/16/how-too-much-screen-time-affects-kids-bodies-andbrains/?sh=1450ca241549

36. Wong, C. W., Tsai, A., Jonas, J. B., Ohno-Matsui, K., Chen, J., Ang, M., \& Ting, D. (2021). Digital Screen Time During the COVID-19 Pandemic: Risk for a Further Myopia Boom?. American journal of ophthalmology, 223, 333-337. https://doi.org/10.1016/j.ajo.2020.07.034

37. Walsh, J. J., Barnes, J. D., Cameron, J. D., Goldfield, G. S., Chaput, J. P., Gunnell, K. E., Ledoux, A. A., Zemek, R. L., \& Tremblay, M. S. (2018). Associations between 24 hour movement behaviours and global cognition in US children: a cross-sectional observational study. The Lancet Child \& Adolescent Health, 2(11), 783-791. https://doi.org/10.1016/s2352-4642(18)30278-5 